\title{
An Analysis of passenger Security Process Based on Petri Net
}

\author{
Haoran $\mathrm{Wu}^{1, \mathrm{a}^{*}}$ \\ ${ }^{1}$ North China Electricity Power University \\ No.2, Beinong Road, Huilongguan, Changping District, Beijing, 102206, P.R.China \\ awu502962982@163.com \\ *The Corresponding author
}

\section{Keywords: Petri net model; Markov chain; Security process}

\begin{abstract}
In order to optimize the passenger security process, in the paper, a passenger security service process of an international airport in the United States were analyzed and a detailed Petri network model were given. Then, the Markov chain, which is isomorphic to the model were established according to the reach-ability table of Petri net, to analyze the performance of the model. Through compute the stable probability distribution of each state of the Markov chain, the performance indexes such as the average tokens number and resource utilization rate of each link were obtained. The analysis found the mainly reasons to cause the delay.
\end{abstract}

\section{Introduction}

As air travel develops into an increasingly common and indispensable traveling method in recent years, it's a matter of great urgency for us to take new measures to balance between safety and convenience during the airport security process. Many as the attempts we've made, the time spent on the security check is still annoying to most people, for some essential procedures to ensure public safety cannot be omitted arbitrarily. Therefore, it's vital for us to identify the "bottlenecks" of the security process and provide some potential modifications without reducing the security level. And provide some intelligent, automated solutions [1].

\section{Petri Net Model}

Model Introduction. Basic Petri net consists of place, transition and arc in form. Place is the element to represent state, while transition is the element to represent state's change. Transition's function is to change state, which means it can change product's physical and else's property. Place determines whether transition can take place or not. It provides ingredient for the occurrence of transition. Some kind of dependency exists between place and transition. By representing this dependency with directed arc can we construct a Petri net $[2,3]$.

Use net's basic theory to model airport security process. This model needs following basic elements.

Transition: represented by black rectangle. Transition can also called as event node. It represents airport's assistant work-such as ID check, X-ray scanning-to help passengers check in in passenger flow.

Place: represented by hollow circle. Place is status element. It represents passengers in airport passenger flow.

Token: represented by black point. Tokens are stored in place. It represents the amount of passengers in airport passenger flow.

Directed arc: represented by arrow. It links place and transition, showing the direction [4].

Modeling and simulating the system flow model with Visual Object Net ++ can not only reduce the workload, but also prove the model correctness. What's more, it allows us to identify errors like deadlock and clash intuitively, which greatly simplify the analyzing process.

Establishment of Petri Net Model. The model of security process is a concurrent process. When passenger is going through security inspection, the luggage is going through check too. After they both finish the check, the process is over. Two selective transition of same performance is 
involved in the modeling process, which is passengers and their luggage are both faced with the possibility to trigger the alarm. If the alarm is triggered, airport officers should check passengers thoroughly or deal with them $[5,6]$. The security Petri net is as shown:

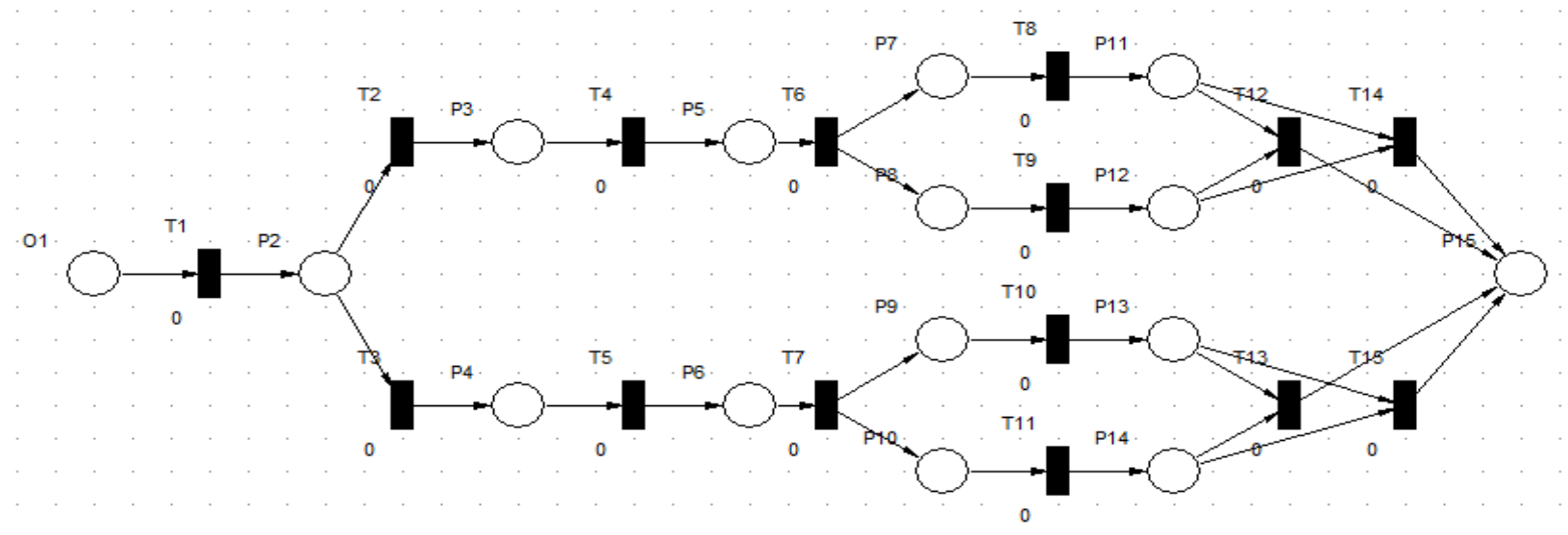

Figure 1. Finite Petri Net

Table 1 Symbol Description

\begin{tabular}{|c|c|c|c|}
\hline $\mathrm{O} 1$ & security entrance & T1 & $\begin{array}{l}\text { judging TSA Pre-Check or regular } \\
\text { check }\end{array}$ \\
\hline$\overline{\mathrm{P} 2}$ & waiting before entry & $\bar{T} 2$ & queuing before TSA Pre-Check \\
\hline$\overline{\mathrm{P} 3}$ & aiting before TSA Pre-Check & T3 & queuing before regular check \\
\hline$\overline{\mathrm{P} 4}$ & waiting before regular check & T4 & ID check \\
\hline$\overline{\mathrm{P} 5}$ & $\begin{array}{l}\text { waiting before security } \\
\text { Pre-Check) }\end{array}$ & T5 & ID check \\
\hline P6 & waiting before security check (regular check) & T6 & $\begin{array}{l}\text { placing luggage and belongings (TSA } \\
\text { Pre-Check) }\end{array}$ \\
\hline P7 & $\begin{array}{l}\text { luggage waiting for security check (TSA } \\
\text { Pre-Check) }\end{array}$ & T7 & $\begin{array}{l}\text { placing luggage and belongings } \\
\text { (regular check) }\end{array}$ \\
\hline P8 & $\begin{array}{l}\text { passenger waiting for security check (TSA } \\
\text { Pre-Check) }\end{array}$ & T8 & luggage check (TSA Pre-Check) \\
\hline P9 & $\begin{array}{l}\text { luggage waiting for security check (regular } \\
\text { check) }\end{array}$ & T9 & passenger check (TSA Pre-Check) \\
\hline P10 & $\begin{array}{l}\text { passenger waiting for security check (regular } \\
\text { check) }\end{array}$ & T10 & luggage check (regular check) \\
\hline P11 & $\begin{array}{l}\text { luggage waiting for safety confirmation (TSA } \\
\text { Pre-Check) }\end{array}$ & T11 & passenger check (regular check) \\
\hline P12 & $\begin{array}{l}\text { passenger waiting for safety confirmation } \\
\text { (TSA Pre-Check) }\end{array}$ & T12 & $\begin{array}{l}\begin{array}{l}\text { manual check at D area } \\
\text { Pre-Check) }\end{array} \\
\end{array}$ \\
\hline P13 & $\begin{array}{l}\text { luggage waiting for safety confirmation } \\
\text { (regular check) }\end{array}$ & T13 & $\begin{array}{l}\text { manual check at D area (regular } \\
\text { check) }\end{array}$ \\
\hline P14 & $\begin{array}{l}\text { passenger waiting for safety confirmation } \\
\text { (regular check) }\end{array}$ & T14 & $\begin{array}{lll}\text { reach personal luggage } & \text { (TSA } \\
\text { Pre-Check) } & & \\
\end{array}$ \\
\hline D15 & security check finish & T15 & reach personal luggage (regular check) \\
\hline
\end{tabular}

Simulation Data Processing and Result Analysis. After gain the security process net model by using network simulation platform, to verify whether the token in the model can move smoothly and whether any improper phenomenon like deadlock, dead transition and unreachable tree exists, we should conduct simulated analysis about the net.

Visual Object Net ++ is used to analysis the petri net. Every media-token in this workflow net is reachable to the initial token, and can reach the final place through a series of transition. When the whole process comes to end, initial token transits to final token, and meeting the request that final 
place is not empty. What's more, this workflow net doesn't have dead transition. Therefore, we can prove our Petri net model is rational and reliable.

\section{Model Performance Analysis}

In order to facilitate the analysis, it is a live and recycle closed loop in the process of constructing the reachable identification map. In order to facilitate the analysis, it is possible to add a time transition $\mathrm{T}^{*}$ (The initiation rate is $\lambda^{*}$ ) between the starting place and the ending place, to guarantee reachability diagram is a closed continuous loop.

According to the reachable token map of the security process, the Markov chain can be established. Because the reachable token M0, M1 is not a specific time length, it is an instantaneous transition, so it should be deleted in the process of establishing the homomorphic Markov chain. And the delay time on the model's reachability map should be replaced by the average initiation rate of the corresponding transition. The isomorphic Markov chain of the security process after the substitution is shown as follows:

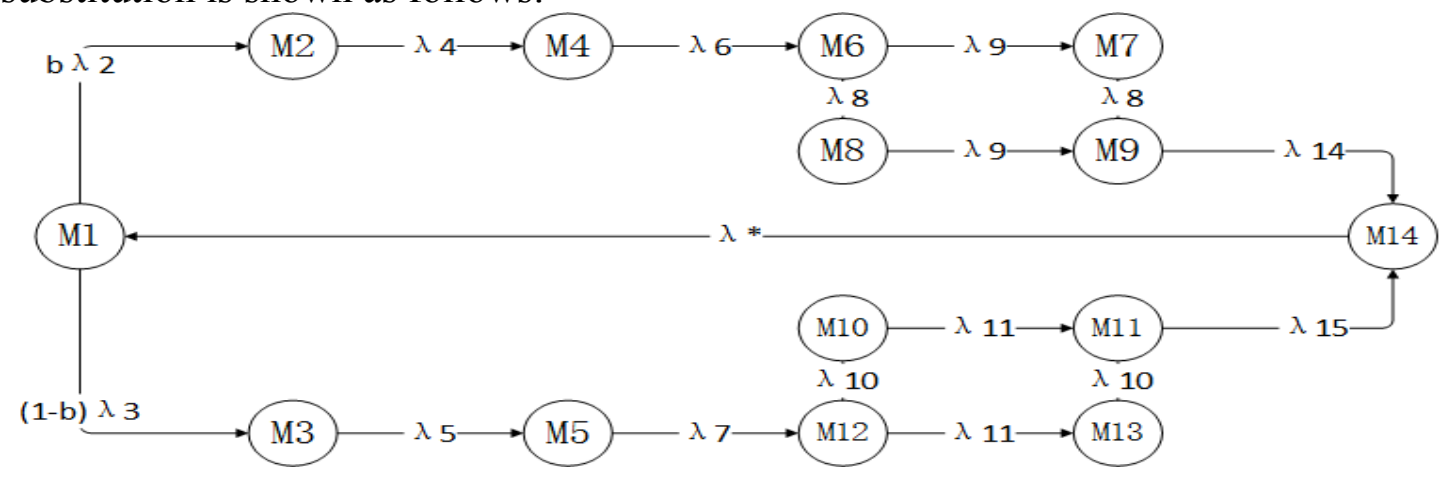

Figure 2. Finite Reachability Diagram

As the security system is complex, while there may be many aspects of the bottleneck, in order to fully analyze the shortcomings of the system, our performance analysis of the security system is based on the use of hierarchical analysis method.

\section{Example Data Analysis}

By analyzing a passenger security service process of an international airport in the United States, we notice that service times are in line with a negative exponential distribution. Thus, we use the data in the title can obtain all aspects of the transition parameters are as follows:

Table 2 The Transition Parameters

\begin{tabular}{|c|c|c|c|c|c|}
\hline Transition (T) & Delay time (S) & Initial rate $(\lambda)$ & Transition $(\mathrm{T})$ & Delay time $(\mathrm{S})$ & Initial rate $(\lambda)$ \\
\hline $\mathrm{T} 2$ & 9.18 & 0.109 & T9 & 0.82 & 1.220 \\
\hline $\mathrm{T} 3$ & 11.72 & 0.085 & $\mathrm{~T} 10$ & 24.18 & 0.041 \\
\hline $\mathrm{T} 4$ & 11.21 & 0.089 & T11 & 0.82 & 1.220 \\
\hline $\mathrm{T5}$ & 11.21 & 0.089 & T12 & ------------------- & ----------------- \\
\hline T6 & 1.5 & 0.667 & $\mathrm{~T} 13$ & ------------------ & ------------------ \\
\hline $\mathrm{T} 7$ & 3 & 0.333 & $\mathrm{~T} 14$ & 1.5 & 0.667 \\
\hline $\mathrm{T} 8$ & 24.18 & 0.041 & $\mathrm{~T} 15$ & 3 & 0.333 \\
\hline
\end{tabular}

Since $45 \%$ of the passengers are involved in the TSA Pre-Check, it is easy to see that $b=0.45$.

Analysis about X-ray Machine. Substitute the rate of initiation of the appeal into the model results obtained when the model performance is analyzed above. According to the formula and $\mathrm{X}$-ray examination of the status of the identification formula to derive the results, we can obtain the probability of steady state probabilities $\mathrm{P}$ [Mi]. The average number of Token numbers in X-ray 
scanning petri-net model database indicates the free status of personnel and equipment. According to the formula of average tokens number of library, the average Token numbers of X-ray scanning petri net system are shown in the following table:

Table 3 The Average Token Numbers of X-ray Scanning

\begin{tabular}{|l|l|l|l|}
\hline Place $(\mathrm{P})$ & Token number & Place $(\mathrm{P})$ & Token number \\
\hline P5 & 0.070936 & P11 & 0.822659 \\
\hline P7 & 0.034058 & P12 & 0.070936 \\
\hline P8 & 0.034058 & P15 & 0 \\
\hline
\end{tabular}

As can be seen from the table, the majority of Token are concentrated in the place P11 out, where the representative of the meaning of the passengers have completed their own security work is waiting for baggage to complete the security check, the results show that in this X-ray scanning system, X-ray scanning baggage this link has become the bottleneck restricting the efficiency of the entire system, the delay accounted for $82.2 \%$ of the entire system, greatly reducing the overall system efficiency.

Analysis about the Entire Security Process. By the same way, the average Token numbers of security system petri net system are shown in the following table:

Table 4 The Average Token Numbers of Security System

\begin{tabular}{|l|l|l|l|}
\hline Place $(\mathrm{P})$ & Token number & Place $(\mathrm{P})$ & Token number \\
\hline P2 & 0.217085 & P5 & 0.256963 \\
\hline P3 & 0.119129 & P6 & 0.256963 \\
\hline P4 & 0.114316 & P15 & 0 \\
\hline
\end{tabular}

As can be seen from the table, there are more tokens in places P2, P5, P6, which represent the waiting time before ID check and X-ray scanning. The results show that in the security system, besides the bottlenecks restricting the efficiency of the system, which exist at X-ray scanning, ID check, will also lead to the accumulation of human traffic, whose delay accounts for $21.7 \%$ of the entire security system. Noting that besides the optimization of X-ray scanning link, we also need to optimize the process of ID check.

\section{Test of the Results}

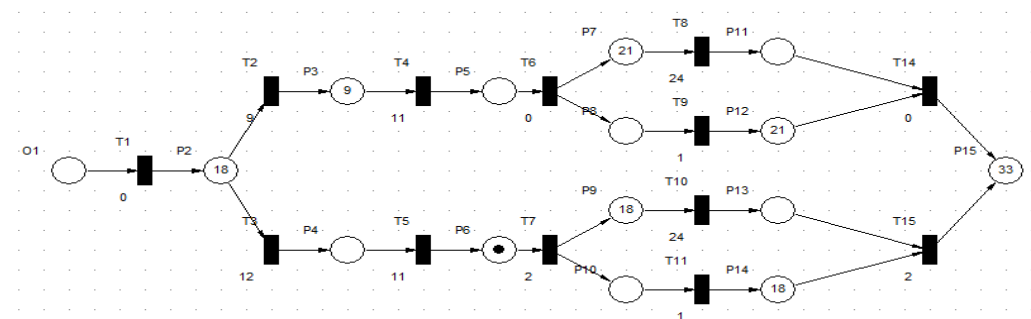

Figure 3. Finite Petri Net simulation

The above figure shows the results obtained by the Visual Object Net ++ software. The black dot in the place and the Arabic numerals represent the token number. It can be seen that the simulation results are in a high degree of consistency with the results obtained by using the Markov chain analysis petri net model, proving that the method and model are of high accuracy and practicality.

\section{Conclusion}

Through the simulation of the security system and analysis of its performance, we found that the bottleneck restricting the security system is mainly concentrated in two aspects: one is before the ID 
check, a large flow of people will be generated in the part of siltation, resulting in a large part of people waiting for long time here; the other is when luggage's going through X-ray, due to the imbalance of the speed of luggage's check and passenger's check, most people have to wait for their luggage after their own check, making the efficiency greatly reduced.

\section{References}

[1] Jun Yang: Setup and Optimization of Security Facilities of Medium-sized Airport, Electronics World, 2015, No.15, p.195 (In Chinese).

[2] Guoyang Jia: Study on Optimization of Terminal Passenger Screening Service Process Based on LCIOWF (MS., Harbin Institute of Technology, China, 2015), p.20 (In Chinese).

[3] Jiangtao Qin: Research on Manufacturing System Performance Analysis Based on Simulation of Petri Net, Industrial Engineering and Management, Vol. 19 (2014) No.1, p.8 (In Chinese).

[4] Yang Bai and Jinfu Zhu: Analysis of Air Cargo Export Handling System Based on Stochastic Petri Net, Journal of Applied Statistics and Management, Vol. 31 (2012) No.2, p.200 (In Chinese).

[5] Bo Yuan: Research and Analysis on the Security Management System of Kunming Changshui International Airport (MS., Yunnan University, China, 2016), p.7 (In Chinese).

[6] Zhenwu Zhao and Jianjun Ma: Tendency and Research on the Queue System of Airport Security Check, China Transportation Review, Vol. 38 (2016) No.10, p.64 (In Chinese). 